\title{
Synergism of the Binary Wear Process of Machinery Elements Used for Gaining Energy Raw Materials
}

\author{
Andrzej N. Wieczorek ${ }^{1, *(1)}$ and Mateusz Wójcicki ${ }^{2}$ \\ 1 Faculty of Mining, Safety Engineering and Industrial Automation, Silesian University of Technology, \\ Akademicka 2 Street, 44-100 Gliwice, Poland \\ 2 Division of Machines and Equipment, KOMAG Institute of Mining Technology, Pszczyńska 37 Street, \\ 44-101 Gliwice, Poland; mwojcicki@komag.eu \\ * Correspondence: andrzej.n.wieczorek@polsl.pl; Tel.: +48-32-237-15-84
}

Citation: Wieczorek, A.N.; Wójcicki, M. Synergism of the Binary Wear Process of Machinery Elements Used for Gaining Energy Raw Materials. Energies 2021, 14, 1981. https:// doi.org/10.3390/en14071981

Academic Editors:

Nikolaos Koukouzas and

Dariusz Prostański

Received: 2 March 2021

Accepted: 30 March 2021

Published: 2 April 2021

Publisher's Note: MDPI stays neutral with regard to jurisdictional claims in published maps and institutional affiliations.

Copyright: (c) 2021 by the authors. Licensee MDPI, Basel, Switzerland. This article is an open access article distributed under the terms and conditions of the Creative Commons Attribution (CC BY) license (https:// creativecommons.org/licenses/by/ $4.0 /)$.

\begin{abstract}
During an in-situ operation of machines, used for the exploitation of energy raw materials, a damaging impact of the environment on the components of these machines is experienced. The action of degrading factors is mostly shown in the form of a clear synergistic effect. In particular, this effect can be seen during an exploitation of driving elements of scraper conveyors, used as one of the basic machines in the hard coal mining process. In the article, the subject-matter, connected with an operation of sprockets in scraper conveyors, is presented. Special attention is paid to a mutual reaction of the mineral abrasive and the presence of mine water. The main objective of the research work was a determination of the interactive component of the factor causing an abrasive wear-quartz abrasive connected with the associated action and the factor intensifying electrochemical corrosion-water with and without the $\mathrm{NaCl}$ salt content. Experimental tests were conducted in the conditions similar to the reality, with the use of a test rig in the form of a short scraper conveyor. Within the framework of the test abrasive wear rates for the case of the abrasive presence itself and a mixture of the abrasive, salt and water were determined. Based on the obtained results, it appears that there is a synergistic impact of abrasive-corrosive mixtures on the wear of the surface layer of the chain sprockets under testing, and also, the causes of the interactive component values in the function of hardness and maximum strength of the materials under investigation are presented.
\end{abstract}

Keywords: wear; scraper conveyors; tribocorrosion

\section{Introduction}

At present, when drifting underground headings, drifting methods based on blasting technologies or involving heading machines are used. In each of the above-mentioned cases, scraper conveyors can be used to transport the crushed rock from the mine face. Due to difficult operational conditions in the corridor workings of mineral resource mines, chain drums are the most critical elements of these conveyors. The most important factors responsible for a degradation of components of scraper conveyors include [1,2]:

- $\quad$ a presence of rock dust in the area of mating between the drums and the chain;

- a corrosive action of the water from sprinkler systems of heading machines and the water flowing from workings;

- numerous successful and unsuccessful start-ups of drives of armoured face conveyors;

- $\quad$ overloads caused, inter alia, by overloading and blocking of the conveyors.

The occurrence of the above-mentioned degradation factors during the operation of scraper conveyors determines the form of damage to the chain drums of conveyors; at the same time, this damage usually has a complex form, e.g., in addition to the abrasive or tribocorrosive wear of the teeth, their fractures or surface deformations are also observed. The most common damage to the chain drums appears in the teeth, but fractures in the bushings connecting individual chain wheels occur as well. 
Particularly intensive destruction processes of conveyor components, including chain drums, are observed when drifting corridor workings in rocks of poor workability, such as sandstone, because the presence of crushed sandstone grains or other hard rocks in the area of mating between the chain wheel and the chain significantly accelerates the degradation of the surface of the seats of these wheels, which is often accompanied by fractures and chipping of the teeth as well as plastic deformations of mating areas.

Depending on the given working, the amount of accessing the excavated material may vary significantly. There are dry workings, where water in the excavated material can come only from the sprinkler system of a heading machine. In such a case, grains of the abrasive material are the only predominant destructive factor (Figure 1A). The crushed rock from the working zone after passing through the conveyor discharge zone reaches the area of mating between the chain drum and the chain, where intensive wear of the surfaces of these components takes place. However, there are also workings in which mine water flows out. In this case, it mixes with rock dust and then enters the areas of mating between the chain wheel and the chain (Figure 1B).

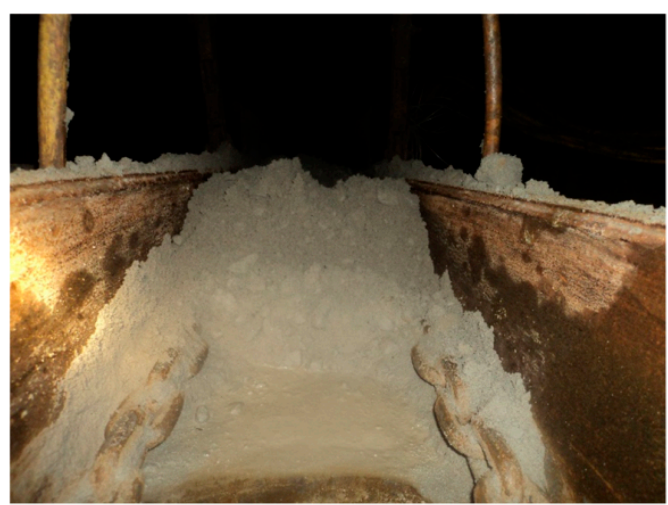

A

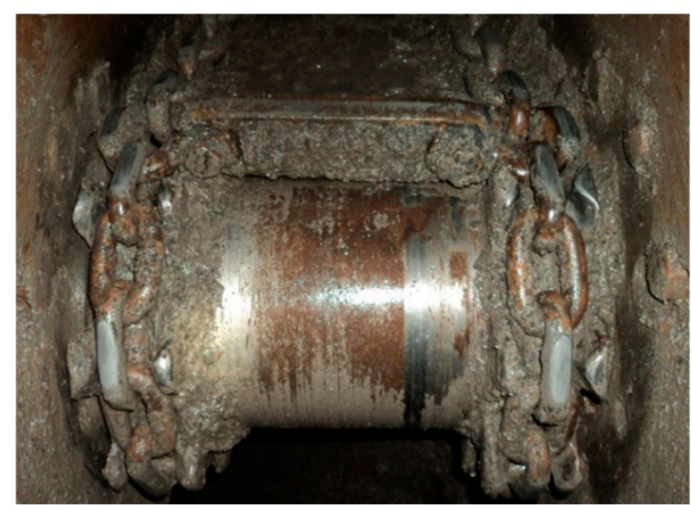

B

Figure 1. Examples of the presence of dry mineral abrasive (A) and mixture of water with abrasive (B) on transmission elements in corridor conveyors.

The mixture of mine water and rock abrasive material causes tribocorrosive wear that represents the combined action of abrasive wear and corrosive wear. The essence of this process is presented later on in this article. A further implication of the presence of crushed rock and a mixture of water and abrasive is the possibility of filling the seats of the chain drum seats and lifting the chain link-then the way of mating in the conveyor drive system changes.

For each combination of at least two environmental factors, the synergy of destructive processes may occur. The measure of this synergy includes the interaction components resulting from the action of a given factor. Wieczorek [3] has considered the situation of the joint action of abrasive wear and dynamic forces, as well as demonstrated the synergy effect accompanying the action of both these factors. In addition, Wieczorek et al. [4] showed a good consistency between the laboratory test of tribocorrosion of austempered ductile irons (ADI) with the test in operational conditions.

This paper presents the results of the interaction component, characterizing the synergy of degradation processes caused by abrasive and corrosive factors, occurring at the construction of underground corridor workings, taking into account the grades of cast steel commonly used in the construction of mining machines.

The process of wear, caused by two factors (abrasive and corrosive), is defined as tribocorrosion [5], which is relatively well-recognised and described. Tribocorrosive wear most often occurs in the tribological systems, composed of two or three elements moving against one another (Figure 2) in the presence of abrasive and corrosive agents [5-7]. 
Thus, tribocorrosion [8] can be defined as the process of wear determined by the simultaneous impact of mechanical inputs and a corrosive environment. In these conditions, abrasive and electrochemical processes interact and this interaction results in an additional synergistic component.
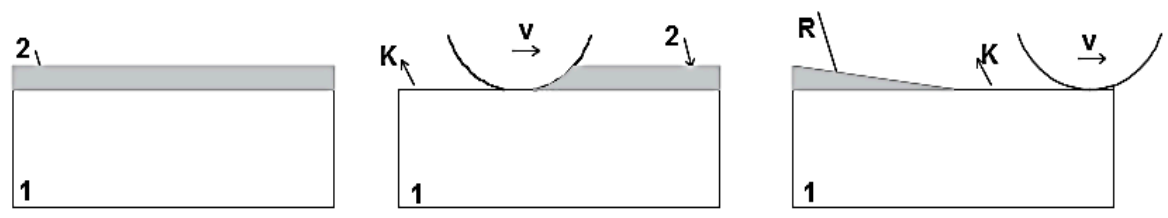

A

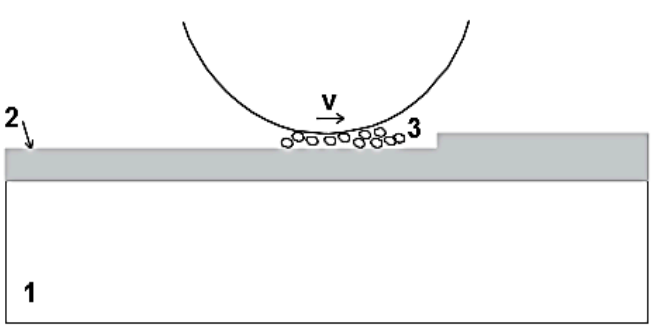

B

Figure 2. Diagram of the tribocorrosive wear mechanism: (A)-intensification of the corrosion process due to friction, (B)-intensification of the wear process due to the action of oxide layer particles; designations: 1-base material, 2-oxide layer, 3-crushed particles of the oxide layer, $\mathrm{R}$-repassivation, $\mathrm{K}$-corrosion, $\mathrm{v}$-sliding velocity.

The synergistic effect, occurring during the tribocorrosion process, results from removing the layer of oxides through friction, which accelerates the surface wear in the exposed and rough places. Furthermore, the hard particles of the removed oxide layers may intensify the destruction of the outer layer [8,9]. Tribocorrosion may also take place in the presence of an additional abrasive, which may intensify this type of wear. The mechanism of tribocorrosive wear is presented in Figure 2.

The mechanism of the combined impact of corrosion and mechanical wear is described by the Watson model [10] which assumes the existence of synergy between both impacts. According to this concept, the total wear $\left(V_{C}\right)$ is the sum of wear caused by the mechanical impacts without corrosion $\left(V_{M}\right)$, the impact of corrosion without friction $\left(V_{K}\right)$ and wear as a result of synergy $(\Delta V)$, where this effect is the sum of the component resulting from the impact of friction on corrosion $\left(V_{M \rightarrow K}\right)$ and the component resulting from the impact of corrosion on friction $\left(V_{K \rightarrow M}\right)$. The above process may be described with the following equation:

$$
V_{C}=V_{M}+V_{K}+\Delta V=V_{M}+V_{K}+\left(V_{M \rightarrow K}+V_{K \rightarrow M}\right)
$$

where: $V_{C}$ is the total wear, $V_{M}$ is the wear caused by mechanical impacts, $V_{K}$ is the wear caused by corrosion impact, $V_{M \rightarrow K}$ is the component resulting from the impact of friction on corrosion, and $V_{K \rightarrow M}$ is the component resulting from the impact of corrosion on friction.

The aforementioned synergism of tribocorrosion wear was experimentally demonstrated by many researchers [11-18]. However, not many research projects have investigated the process of synergistic tribocorrosive wear of real tribological. In the research works by Tyczewski [19-21], possible combinations of factors intensifying the destructive processes were analyzed and the modified Watson model adapted to the specific character of the sugar industry was presented. Complex multi-type abrasive, corrosive and mechanical wear is observed in it. Other results of the research on tribocorrosion of real objects are presented in [22-24]. 
In the case discussed herein, the tribocorrosion process was initiated in the variant intensified by a quartz abrasive which caused deep scratches on the surface. These damages were subject to accelerated corrosion. The corrosion products were also removed from the steel surfaces and mixed with the quartz abrasive. The results of this action demonstrate the characteristics of the synergism of the damaging processes and are the subject of this analysis.

\section{Experimental Details}

The research activities presented in this paper used laboratory measurements of the mass corrosion rate of the investigated steel elements and stand tests of wear under the combined impact of abrasive and corrosive agents. In order to determine the mass corrosion rate, the value of the corrosion current density needs to be known. This parameter was determined using the Solartron 1287 potentiostat with an FRA 1255A impedance system. The object of the tests included cubic samples with the side length of $10 \mathrm{~mm}$, made of the investigated steel, taken from the zone of interaction between the sprocket teeth and chain links.

The stand tests of tribocorrosive wear of the steel alloys were performed using a test stand presented graphically in Figure 3A.

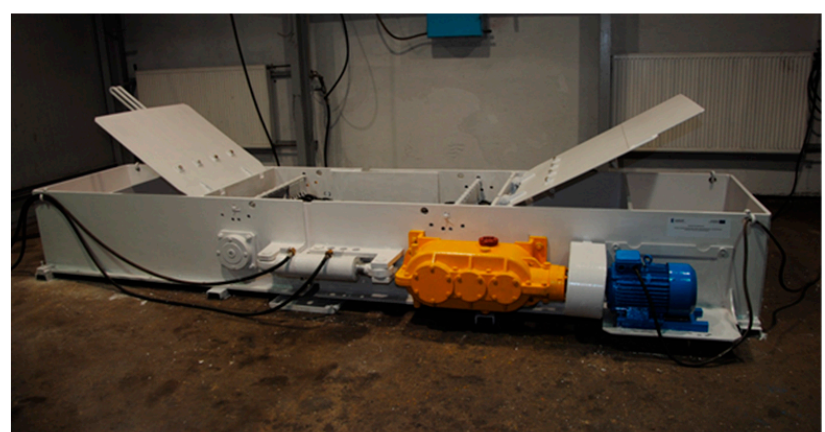

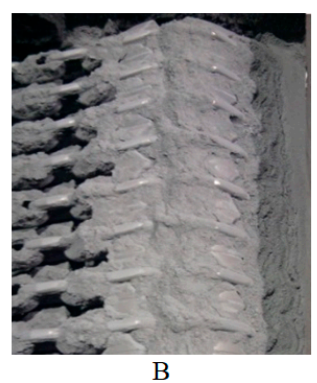

B

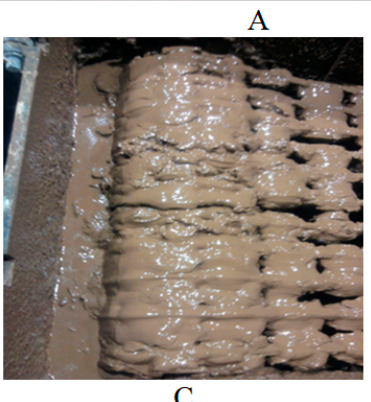

C

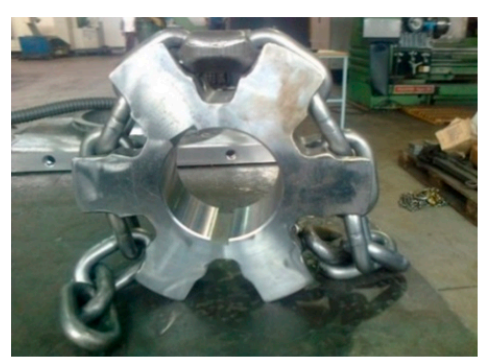

$\mathrm{D}$

Figure 3. Test rig, (A) — rig, (B) — testing chamber filled with dry quartz abrasive, (C) — testing chamber filled with a mixture of quartz sand and water, (D) - tested chain wheel.

The quartz abrasive or its mixture with water and salt was placed in the test chamber (Figure 3B,C) with the tested sprockets. This way, an abrasive or abrasive-corrosive layer was always present between the surface of the sprocket bottom and the chain link. The wear testing method is described in detail in [16]. The wear tests were carried out for $200 \mathrm{~h}$, $100 \mathrm{~h}$ for each direction of the rotation of the sprockets. Their peripheral velocity was $\mathrm{v}$ $=0.7 \mathrm{~m} / \mathrm{s}$ and the input power of each motor was $\mathrm{PM}_{1}=\mathrm{PM}_{2}=7.5 \mathrm{~kW}$. The determined surface pressures between the wheel surface and the chain surface were equal to $48.9 \mathrm{MPa}$, whereas the maximum reduced stress at the base of the tooth was $2.18 \mathrm{MPa}$. The values for surface pressure and the maximum reduced stress by conducting numerical simulations. Sprockets (Figure 3D) made from flame-hardened cast steel alloys: GS42CrMo-4, L35GSM, L30GS, L20HGSNM and A6 were the object of the tests. The mechanical properties of the considered steels are presented in Table 1, while the chemical composition of cast steel is presented in Table 2. 
Table 1. Mechanical properties of the tested cast steel.

\begin{tabular}{cccc}
\hline Materials & $\begin{array}{c}\text { Tensile Strength TS, } \\
\text { MPa }\end{array}$ & $\begin{array}{c}\text { Yield Strength YS, } \\
\mathbf{M P a}\end{array}$ & Elongation A5, \% \\
\hline GS42CrNiMo-4 & 1115 & 905 & $8.9 \pm 0.1$ \\
L20HGSNM & 1134 & 1083 & $10.0 \pm 0.1$ \\
L30GS & 632 & 396 & $17.8 \pm 0.1$ \\
A6 & 739 & 526 & $16.3 \pm 0.1$ \\
L35GSM (30CrMo12) & 1152 & 891 & $8.7 \pm 0.1$ \\
\hline
\end{tabular}

Table 2. Chemical composition of cast steel (mass $\%$ ).

\begin{tabular}{ccccccc}
\hline Designation & $\mathbf{C}$ & $\mathbf{S i}$ & $\mathbf{M n}$ & $\mathbf{C r}$ & $\mathbf{N i}$ & Mo \\
\hline GS42CrMo4 & 0.35 & 0.38 & 0.72 & 1.21 & 0.06 & 0.5 \\
L35GSM & 0.36 & 0.67 & 1.27 & - & - & 0.036 \\
(30CrMo12) & & 0.82 & 0.91 & 0.78 & 0.95 & 0.16 \\
20HGSNM & 0.22 & 0.636 & 1.27 & 0.096 & 0.106 & - \\
L30GS & 0.28 & 0.52 & 1.295 & - & - & - \\
A6 & 0.295 & & & &
\end{tabular}

Three sets of sprockets were used for the investigations. Once the tests were completed, samples were taken to study the microstructure, determine the hardness of the top layer and observe the surface damage. Each of the sets was subject to a full wear cycle and the only difference between the testing variants was the type of abrasive used. Table 3 presents the combinations of the abrasive or tribocorrosive agents.

Table 3. Combinations of damaging agents.

\begin{tabular}{cc}
\hline Variant Marking & Abrasive or Abrasive-Corrosive Agents \\
\hline Variant $\mathrm{A}$ & quartz sand $\mathrm{SiO}_{2}$ \\
Variant $\mathrm{C}$ & quartz sand $\mathrm{SiO} 2+\mathrm{water}_{2} \mathrm{O}$ \\
Variant $\mathrm{C}+\mathrm{NaCl}$ & quartz sand $\mathrm{SiO}_{2}+$ approx. $3.5 \% \mathrm{NaCl}$ solution \\
& (the proportion of water in the mixture did not exceed $20 \%$ ) \\
\hline
\end{tabular}

Microscopic studies were performed after the wear tests. Samples for the microstructural tests were cut out from the area of interaction between the sprocket and the chain. The samples were then ground, polished and etched with the $2 \%$ Nital solution. Observations of the microstructure were carried our using the OLYMPUS IX70 microscope with 50 to 1000x magnification and scanning electron microscopes: HITACHI S-3500N and Supra 35 ZEISS with an EDS spectrometer.

The top layer of the cast steel alloys L20HGSNM, GS42CrMo-4, A6, L30GS and L35GSM contained tempered martensite formed in the result of surface hardening, whereas in the core of the sprockets, fine-grained sorbitol was noticed (an example of the microstructure of the top layer of the L20HGSNM steel is presented in Figure 4A. Figure 4B shows an exemplary cross-section through the top layer of the L35GSM steel in the zone located between 0 and $0.05 \mathrm{~mm}$ from the surface. In the presented top layer, some non-metallic precipitates and manganese sulphides are also visible. The non-metallic precipitates were also found in all the tested steels and were usually situated in the areas where the sand came into contact with the melted metal. 


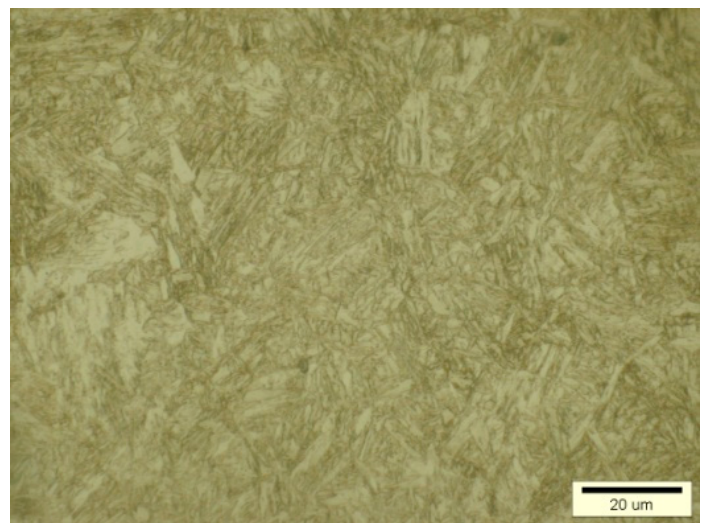

(A)

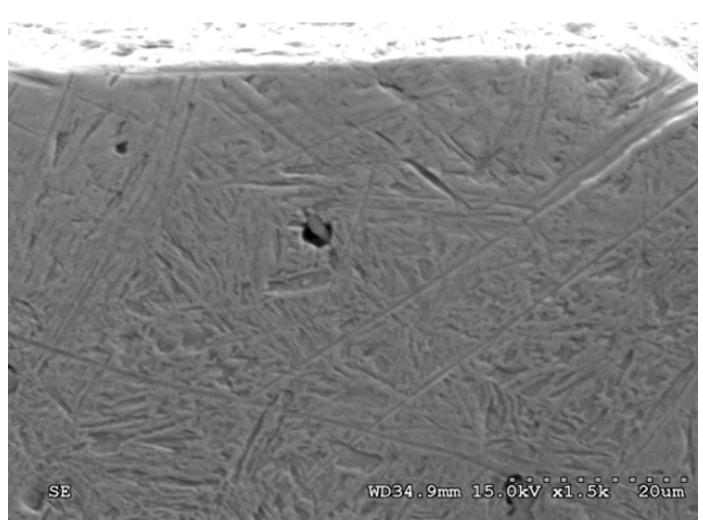

(B)

Figure 4. Microstructure of L20HGSNM steel cast (A) in the area approximately $0.5 \mathrm{~mm}$ under the surface (OM) and cross-section through the top layer of L35GSM (B) steel cast (OM).

In order to determine the abrasive wear of the sprockets, the surfaces of interaction between the sprocket and the chain, before and after the wear test, were measured using a coordinate measuring machine (CMM). The sprocket-chain collaboration area was reflected with at least 300 points which created the path of the probe (the method of determining the wear parameters is presented in [25]).

To determine the wear, the $\delta_{i, N}$ parameter was used, defined as the distance between the positions of the probe before and after the test for the i-th point on the path and $\mathrm{N}$-th tooth of the sprocket. The determined values of the $\delta_{\mathrm{i}, \mathrm{N}}$ wear parameter were averaged for all the measured teeth of the given sprocket, using the following equation:

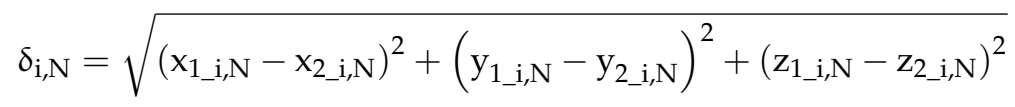

where $x_{1 \_i, N}$ is the $x$ coordinate of the $i$-th point of $N$-th teeth before the test, $x_{2 \_i, N}$ is the $x$ coordinate of the $\mathrm{i}$-th point of $\mathrm{N}$-th teeth after the test, $\mathrm{y}_{1_{-} \mathrm{i}, \mathrm{N}}$ is the $\mathrm{y}$ coordinate of the $\mathrm{i}$-th point of $\mathrm{N}$-th teeth before the test, $\mathrm{y}_{2} \mathrm{i}, \mathrm{N}$ is the $\mathrm{y}$ coordinate of the $\mathrm{i}$-th point of $\mathrm{N}$-th teeth after the test, $z_{1_{-} i, N}$ is the $z$ coordinate of the $i$-th point of $N$-th teeth before the test, $\mathrm{z}_{2 \_\mathrm{i}, \mathrm{N}}$ is the $\mathrm{z}$ coordinate of the $\mathrm{i}$-th point of $\mathrm{N}$-th teeth after the test, and $\mathrm{N}$ is the number of measured teeth.

On the basis of the wear value of the i-th point of the measuring route $\delta_{i, N}$ determined for each $\mathrm{N}$-th tooth, the values $\delta_{\mathrm{i}} \mathrm{AVG}$ averaged in relation to all the measured tooth surfaces of a given chain wheel were determined with the use of the following relationship:

$$
\delta_{\mathrm{i} \_\mathrm{AVG}}=\frac{\sum_{1}^{n} \delta_{\mathrm{i}, \mathrm{N}}}{n}
$$

where $n$ is the number of seat surfaces of a given chain wheel $(n=24)$.

Then, a single number maximum wear ratio $\left(\delta_{\mathrm{MAX}}\right)$ for the given sprocket was determined, using the equation:

$$
\delta_{\mathrm{MAX}}=\frac{\sum_{1}^{n} \operatorname{Max}\left\{\delta_{\mathrm{i}, \mathrm{N}}\right\}}{n}
$$

In addition, based on the $\delta_{\mathrm{i} \_A V G}$ averaged wear values, the logs of this parameter along the adopted measurement path were identified (the logs of this parameter in the function of the number of the measuring point are marked as $\delta_{i_{-}}$AVG $\left.(i)\right)$. The values of $\delta_{i \_A V G}(i)$ express the thickness of the surface layer removed as in the result of the action wear factors at a given point of contact between the chain and the seat. The method of determining the wear parameters $\delta_{i_{\_} A V G}$ and $\delta_{\text {MAX }}$ is shown in Figure 5. 


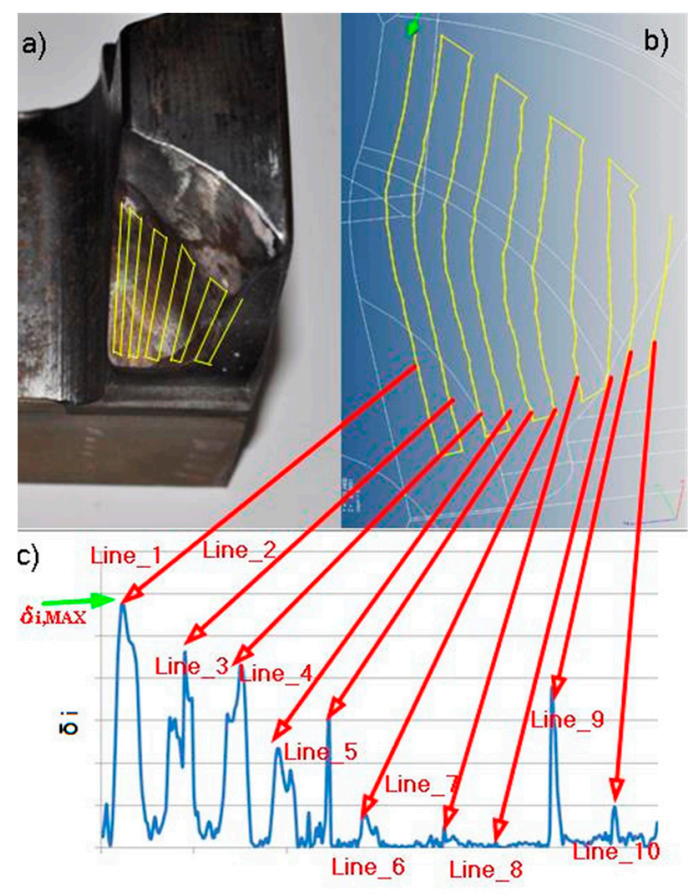

Figure 5. The concept of quantitative assessment of material: (a) the measurement site, (b) the measuring head route, (c) sample results Reproduced from [24], ScienceDirect: 2021.

\section{Results and Discussion}

\subsection{Corrosion Test Results}

Table 4 presents the parameters that characterize the process of electrochemical corrosion of the tested materials. The corrosion potential $\mathrm{E}_{\mathrm{CORR}}$ and corrosion current density $\mathrm{i}_{\text {CORR }}$ in the $3.5 \% \mathrm{NaCl}$ solution were determined using the Tafel simple extrapolation method. The corrosion rate CR [26] was determined from the formula:

$$
C R=\frac{3 \cdot 27 \cdot 10^{-3} \cdot i_{\mathrm{CORR}} \cdot E w}{p}
$$

where: $i_{C O R R}$ is the corrosion current density, $E_{w}$ is the weight of the corroding metal in $\mathrm{g}$, and $p$ is the density of the corroding metal in $\mathrm{g} / \mathrm{cm}^{3}$.

Table 4. Parameters describing the process of electrochemical corrosion of the tested materials.

\begin{tabular}{cccc}
\hline Sample Name & $\begin{array}{c}\text { Corrosion Potential } \\
\mathbf{E}_{\text {CORR }} \mathbf{~ m V}\end{array}$ & $\begin{array}{c}\text { Corrosion Current } \\
\text { Density icoRR, } \\
\boldsymbol{\mu A} / \mathbf{c m}^{2}\end{array}$ & $\begin{array}{c}\text { Corrosion Rate CR, } \\
\mathbf{m m} / \mathbf{y e a r}\end{array}$ \\
\hline L20HGSNM & $-660.5 \pm 14.89$ & $14.95 \pm 2.69$ & $0.1304 \pm 0.085$ \\
GS42CrMo-4 & $-667.25 \pm 16.5$ & $13.21 \pm 0.6$ & $0.151 \pm 0.005$ \\
L35GSM & $-442.3 \pm 35.9$ & $17.53 \pm 1.83$ & $0.166 \pm 0.037$ \\
A6 & $-698.3 \pm 6.5$ & $14.26 \pm 1.35$ & $0.165 \pm 0.01$ \\
L30GS & $-449.3 \pm 34.23$ & $8.44 \pm 2.06$ & $0.154 \pm 0.097$ \\
\hline
\end{tabular}

Based on the presented results, it may be concluded that the corrosion rates of the tested steel alloys are similar, but the L20HGSNM demonstrated the least susceptibility to corrosion. All the tested materials showed corrosive properties; no passivation was noticed (see Figure 6). This is mainly due to the chemical composition of these materials (see Table 2). The results, presented above, will be used later to identify the wear component, where the wear is caused by electrochemical corrosion without friction $\left(V_{K}\right)$. 


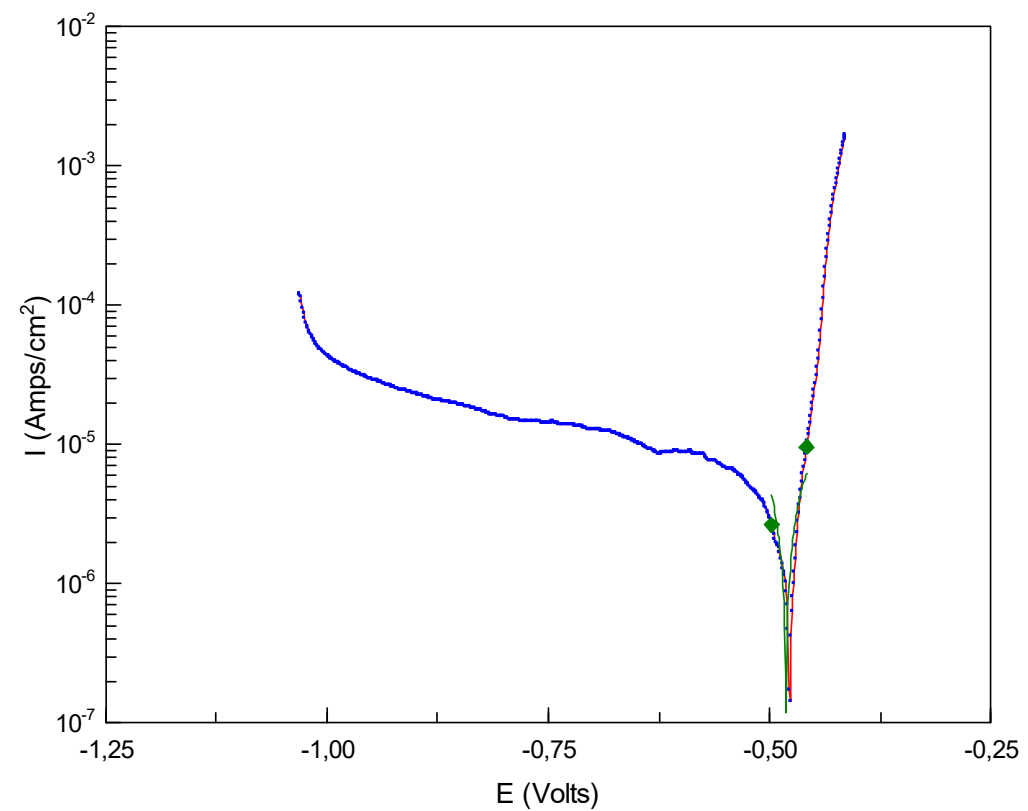

Figure 6. Polarization curve determined for the L30GS steel in $3.5 \% \mathrm{NaCl}$ solution.

\subsection{Identification of Damage Forms Caused during the Stand Tests}

The tested sprockets showed diverse wear values, both related to the material and to the combination of degrading agents. This wear value was determined mainly by the wear mechanism. The stand tests in the conditions of the abrasive wear of the sprockets were performed in the presence of only one degrading agent, quartz sand, whereas in tribocorrosive conditions, they were carried out in the presence of an abrasive-corrosive mixture consisting of quartz abrasive and water or salt and water solution (see Table 3). During the tests, dry or hydrated quartz abrasive was present all the time between the collaborating surfaces, but the size of the grains was changing due to grinding caused by the interacting surfaces (a diagram of this process is presented in Figure 7). The intense grinding of the abrasive was observed during the first $10 \mathrm{~h}$ of the wear test.

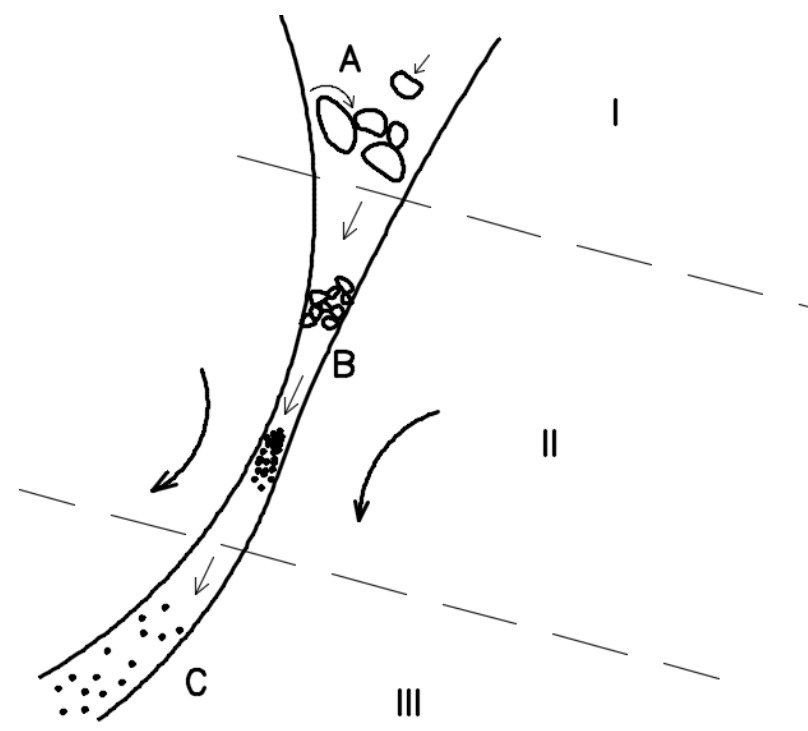

Figure 7. Diagram of the crushing process in the area of mating between the bottom of the seat and the chain link; designations: I-zone of the entry of the abrasive, II-central zone, III-exit zone, A-supply of the abrasive, B-multi-stage crushing, $\mathrm{C}$ - final form of crushing. 
Damaging agents acted mainly in the area of interaction between the sprocket bottom parts and the link chain. In Figure 8, differences between the interaction zones depending on the test variant are presented.
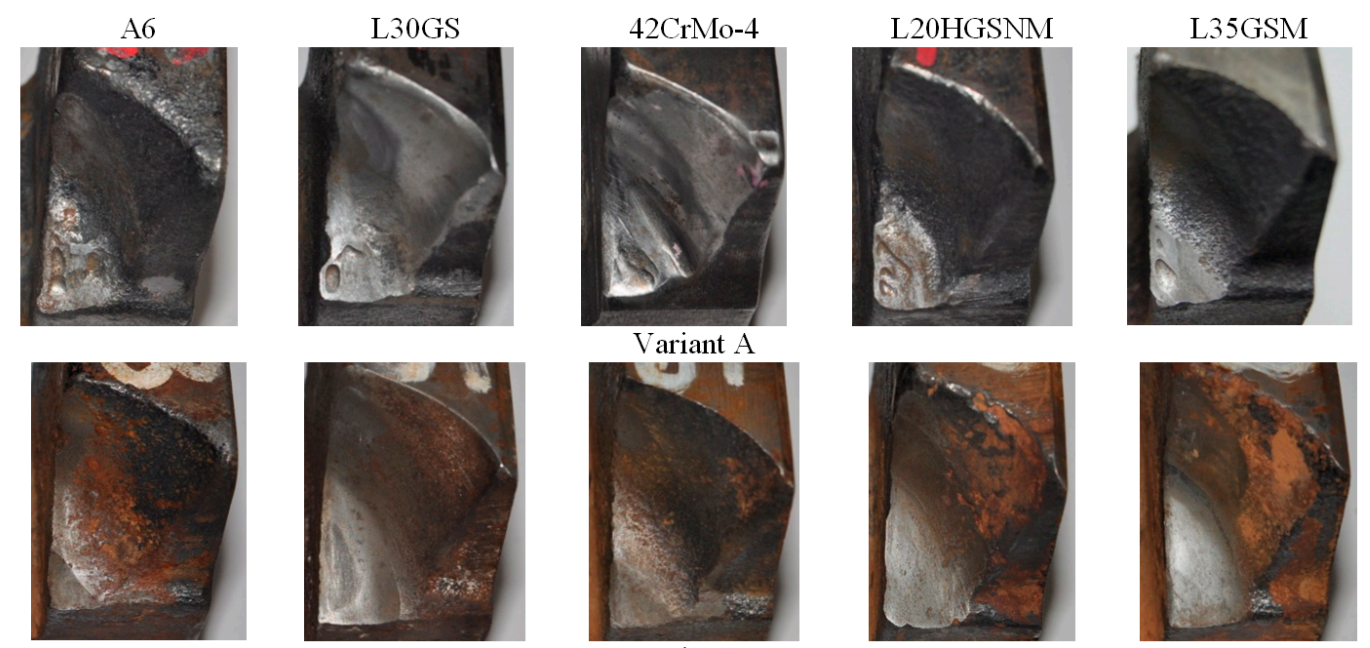

Figure 8. A view of chain wheel sockets after abrasive wear tests.

For the test in abrasive conditions (Variant A), the surfaces have single small elliptic cavities, while in the case of the corrosive-abrasive test (Variant $C$ ), the wear area is smoothed and shows significant lowering of the sprocket bottom parts. As for the abrasive wear test (Variant A) and the surface-hardened L35GSM, L30GS and A6 steel, the impact of the abrasive grains caused a formation of quite deep micro-cuttings on the surface of the sprocket bottom (Figure 9A). The deformation of the micro-chips (Figure 9B) clearly proves that despite the hardening process, the discussed materials kept their plastic strain characteristics.

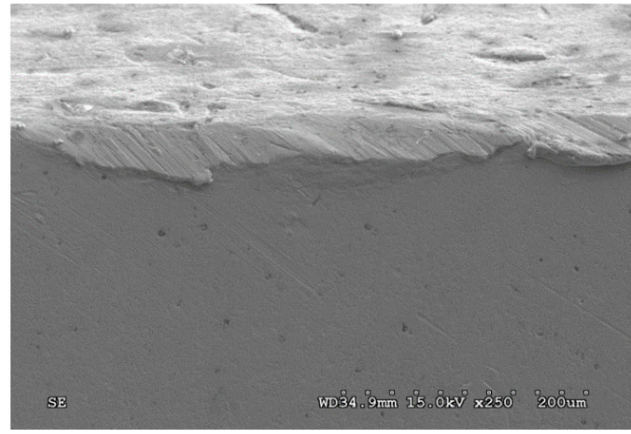

A

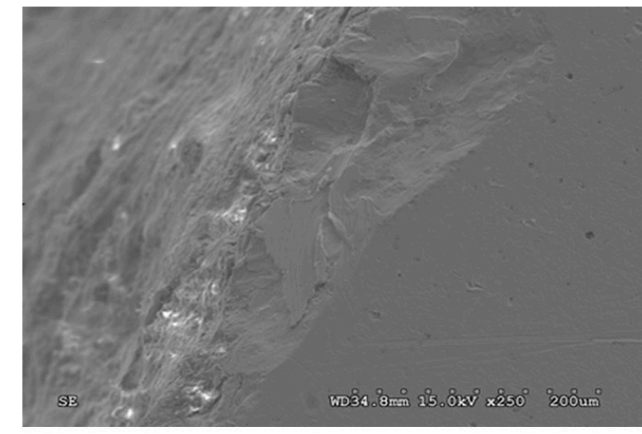

B

Figure 9. Surface micro-cutting marks (A) and deformations (B) of the sprocket made of the L35GSM steel cast, caused by quartz abrasive grains, SEM.

The microscopic analysis of the steels under consideration revealed a few low-cycle fatigue cracks of the surface or damages typical for brittle objects. No impact of different precipitates in the microstructure on the formation of damage other than the ones mentioned before was noticed.

The microscopic analysis of the top layer of the GS42CrMo-4 steel, tested in the conditions of abrasive wear, revealed the following damage forms:

- micro chips caused by the grains of the abrasive and nearby surface cracks (Figure 10A),

- $\quad$ grinding on the top of the uneven surface caused by low-cycle wear (Figure 10B). 


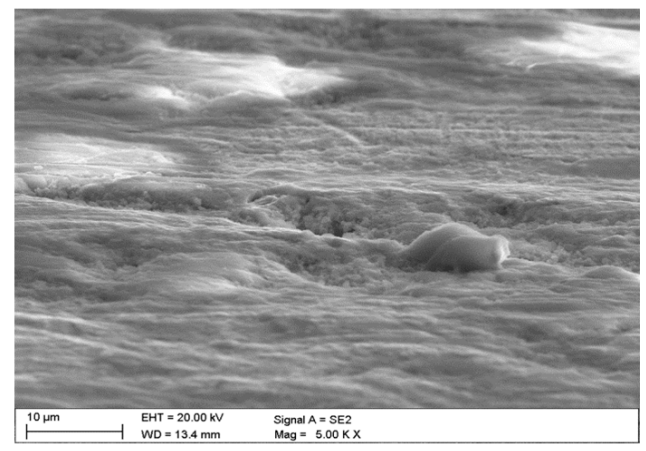

A

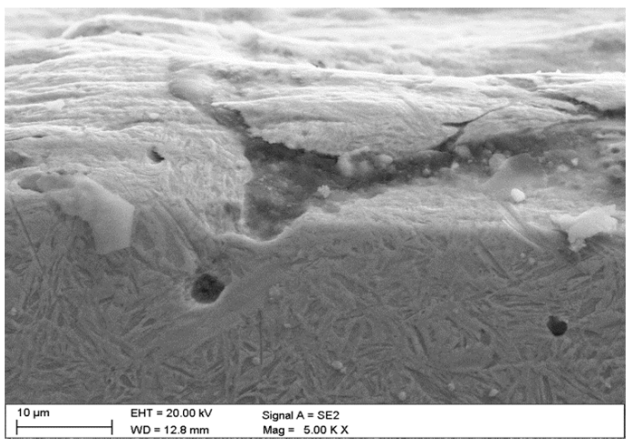

$\mathrm{B}$

Figure 10. Damage to the surface of the wheel made of the GS42CrMo-4 cast steel, (A) — caused by grains of quartz abrasive, (B) - caused by fatigue processes, SEM.

In the case of the L20HGSNM steel, there were marks typical for micro-cutting with grains of the quartz abrasive (Figure 11A) and zones of surface fractures which were transformed further into clearly visible grindings of the top layer (Figure 11B). The revealed surface damage forms prove the presence of the abrasive wear with brittle fractures oriented parallelly to the surface.

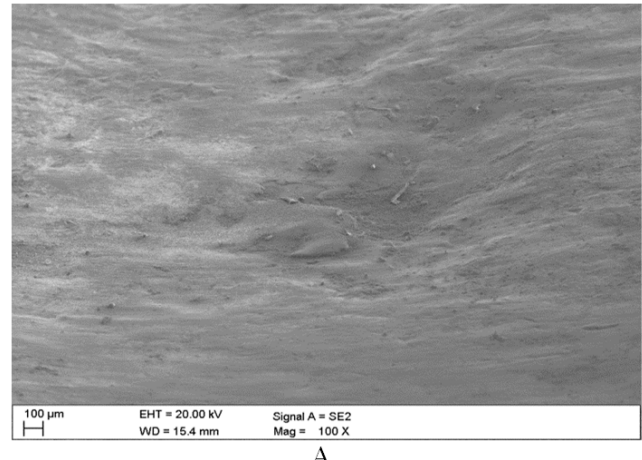

A

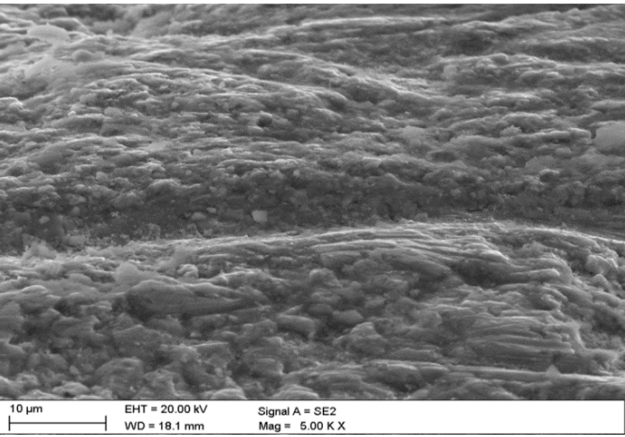

$\mathrm{B}$

Figure 11. Surface damage of the sprocket made of the L20HGSNM cast steel, (A)—micro-cutting marks, (B)—surface fractures, SEM.

Once tested in tribocorrosive conditions (Variant C), the surfaces of the sprockets made of the steels under consideration showed damages typical for micro-scratching of the surface with the abrasive grains and the simultaneously accelerated formation of easily separating layers of iron oxide due to electrochemical corrosion. A characteristic feature of the analyzed surfaces included numerous and deep chips of separated material on the smoothed, collaborating surfaces (Figure 12A). No differences in the form of damages, depending on the material from which the sprockets were made of, were noticed.

In the case of the tribocorrosive test intensified with $\mathrm{NaCl}$ (Variant $\mathrm{C}+\mathrm{NaCl}$ ), only shallow micro-scratches were visible on the worn surfaces. The areas smoothed with the abrasive and covered with corrosion products were visible on the surface of the sprockets made of the investigated steels (Figure 12B). The above observations of the surfaces subject to tribocorrosive wear do not allow to identify other possible forms of damages, for example low-cycle wear, because potential marks were defaced due to an intense formation and separation of the oxide layers caused by the action of the abrasive. 


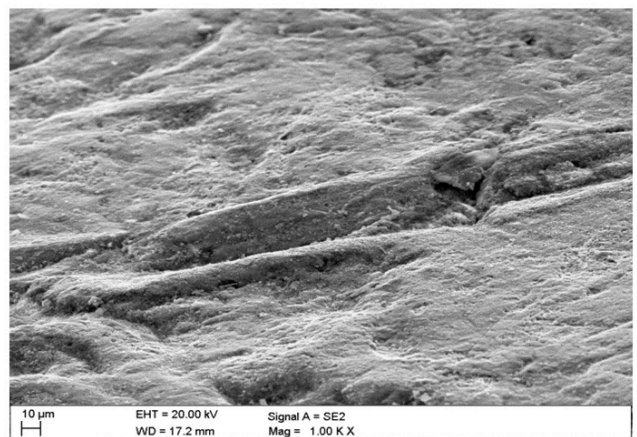

A

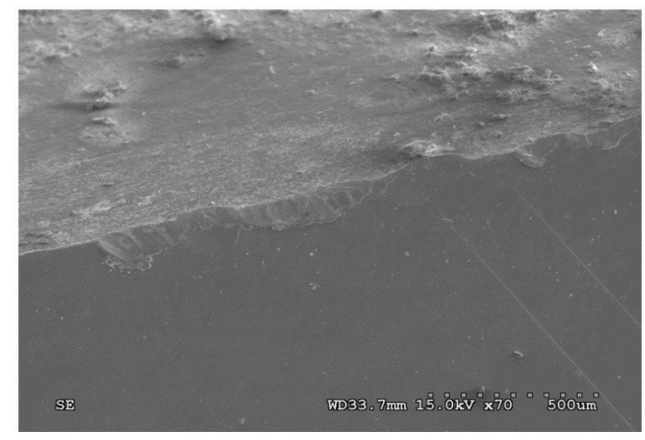

B

Figure 12. Damage to surfaces of the wheels caused by tribocorrosive wear, (A) - a view of micro-cutting traces on the surface of the wheel made of the A6 cast steel (Variant C), (B) - a view of the surface of the wheel made of the L30GS cast steel (Variant $\mathrm{C}+\mathrm{NaCl}$ ), SEM.

\subsection{Stand Tests Results}

The highest values of wear (Figure 13) are observed in the area of contact of the wheel seat with the chain link (the range of the first 150 measurement points of $\delta_{\text {i_AVG }}(i)$ ). Wear values for the parameter $\delta_{i \_A V G}(i)$ are higher for both variants of tribocorrosive wear as compared with the abrasive wear. In addition, it can be noticed in Figure 13 that the wear is intensified by the corrosive action of $3.5 \% \mathrm{NaCl}$ solution. The increased wear of surfaces of the chain wheels was caused not only by the increased rate of corrosion, but also by the mechanical action of corrosion products (mainly iron oxides). This was confirmed by a qualitative change in the abrasive during the wear test in Variant $\mathrm{C}+\mathrm{NaCl}$, which manifested itself by a change in colour from sandy to brown, and a change in consistency from liquid to ductile.

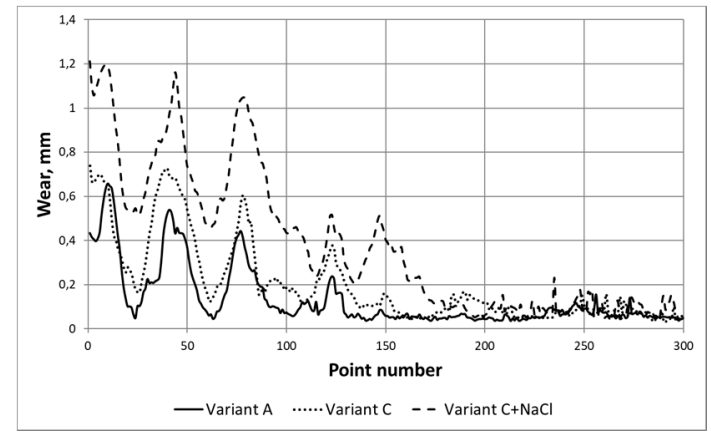

(A) GS42CrMo-4

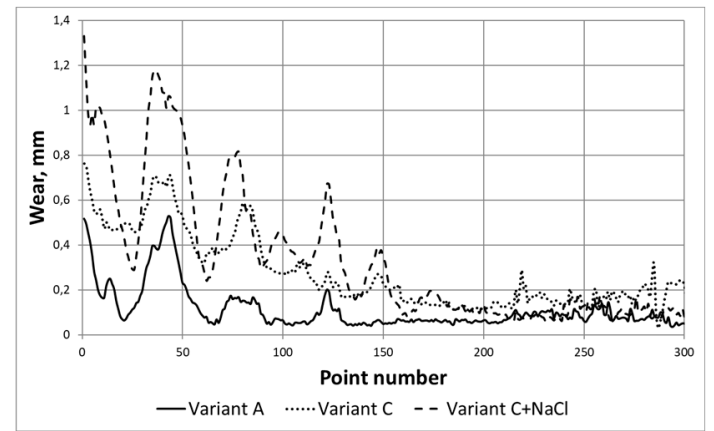

(B) L35GSM

Figure 13. Averaged wear curves $\delta_{i_{-}}$AVG. (A) Determined for GS42CrMo-4 steel casts, (B) Determined for L35GSM steel casts.

Based on the plots of the averaged wear $\delta_{\text {i_AVG }}(i)$, the values of the wear parameter $\delta_{\text {MAX }}$ were determined (Figure 14) for the tested cast steels in the function of maximum strength. Figure 14 also shows that the higher the maximum strength, the lower the total wear. This relation can be easily explained because of the higher hardness of the surface after flame-hardening (see Table 1) of the cast steel alloys (L20HGSNM, GS42CrMo4, L35GSM) as compared to the steels containing mainly manganese in their chemical composition (L30GS, A6). 


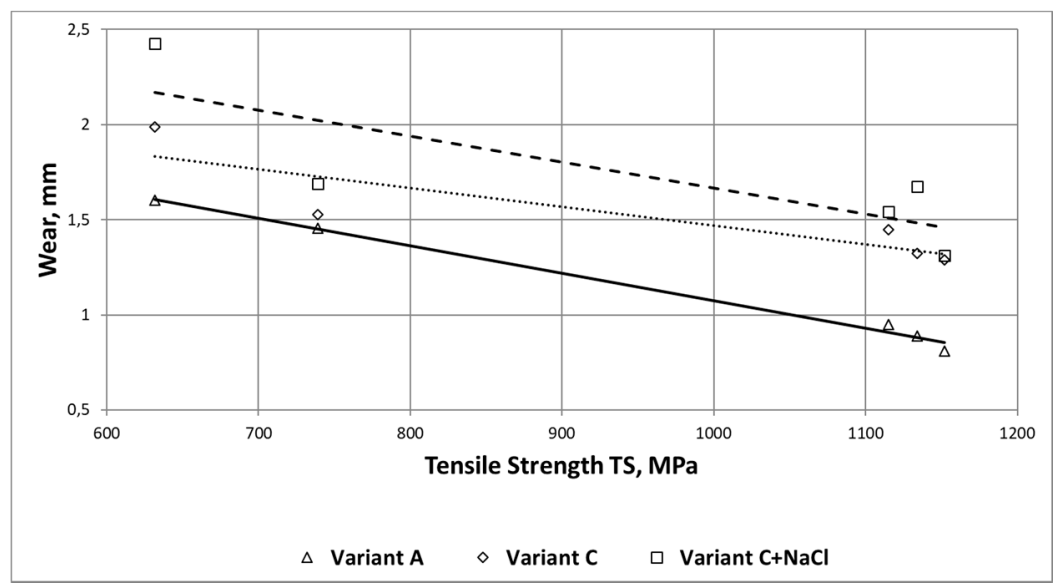

Figure 14. The $\delta_{\text {MAX }}$ wear parameter curves in the function of maximum strength, determined for the analyzed wear variants.

\section{Interaction Components of the Tribocorrosive Wear Process in Chain Drums}

The interactive component, resulting from the synergistic impact of the corrosive and abrasive agents on the wear of the surface of the sprockets $(\Delta V)$ may be determined from the following equation:

$$
\Delta V=\mathrm{V}_{\mathrm{C}}-\mathrm{V}_{\mathrm{M}}-\mathrm{V}_{\mathrm{K}}
$$

The wear component, caused by electrochemical corrosion without friction $\left(\mathrm{V}_{\mathrm{K}}\right)$, represents the thickness of the material removed due to electrochemical corrosion in the conditions without the synergistic impact of the abrasive wear. To determine the $V_{K}$ factor, it was assumed that corrosive wear would not exceed the thickness of the material dissolved in the $3.5 \% \mathrm{NaCl}$ solution. Based on Table 4, this factor was determined assuming the estimated time of the corrosive wear equal to the duration of the stand test, that is, 200 h. The values calculated for the analyzed materials are compared in Table 5.

Table 5. Values of wear caused by electrochemical corrosion not supported by friction VK determined for the analyzed materials.

\begin{tabular}{ccc}
\hline Title $\mathbf{1}$ & $\mathbf{V}_{\mathbf{K}}, \mathbf{m m}$ & $\begin{array}{c}\text { Uncertainty of Measurement, } \\
\mathbf{m m}\end{array}$ \\
\hline L20HGSNM & 0.0030 & 0.0002 \\
GS42CrMo-4 & 0.0034 & 0.0001 \\
L30GS & 0.0035 & 0.0002 \\
A6 & 0.0038 & 0.0002 \\
L35GSM & 0.0038 & 0.0008 \\
\hline
\end{tabular}

The total wear $V_{C}$ value is equal to the $\delta_{M A X}$ wear value after the tribocorrosive test (Variant $\mathrm{C}$ or Variant $\mathrm{C}+\mathrm{NaCl}$ ), while the $\mathrm{V}_{\mathrm{M}}$ component is equal to the $\delta_{\mathrm{MAX}}$ wear value after the abrasive test (Variant A).

Hence, also:

$$
\begin{aligned}
\Delta \mathrm{V}_{\text {Variant } \mathrm{C}} & =\delta_{\mathrm{MAX}, \mathrm{C}}-\delta_{\mathrm{MAX}, \mathrm{A}}-\mathrm{V}_{\mathrm{K}} \\
\Delta \mathrm{V}_{\text {Variant } \mathrm{C}+\mathrm{NaCl}} & =\delta_{\mathrm{MAX}, \mathrm{C}+\mathrm{NaCl}}-\delta_{\mathrm{MAX}, \mathrm{A}}-\mathrm{V}_{\mathrm{K}}
\end{aligned}
$$

Similarly, the curves of the synergistic component in the function of the location on the measured path $\Delta \mathrm{V}(\mathrm{i})$ will take the following form:

$$
\begin{gathered}
\Delta \mathrm{V}_{\text {Variant } \mathrm{C}}(\mathrm{i})=\delta_{\mathrm{MAX}, \mathrm{C}}(\mathrm{i})-\delta_{\mathrm{MAX}, \mathrm{A}}(\mathrm{i})-\mathrm{V}_{\mathrm{K}} \\
\Delta \mathrm{V}_{\text {Variant } \mathrm{C}+\mathrm{NaCl}(\mathrm{i})}=\delta_{\mathrm{MAX}, \mathrm{C}+\mathrm{NaCl}}(\mathrm{i})-\delta_{\mathrm{MAX}, \mathrm{A}}(\mathrm{i})-\mathrm{V}_{\mathrm{K}}
\end{gathered}
$$


Figure 15 presents examples of curves of the $\Delta \mathrm{V}(\mathrm{i})$ interactive component against the location on the measured path for three selected steels and both tribocorrosive wear variants. When analyzing Figure 15, it can be concluded that adding water or a water-salt mixture to the abrasive caused an additional synergistic effect (discussed in the Introduction), that is, destructive processes affecting the surface of the sprockets. The $\Delta \mathrm{V}(\mathrm{i})$ component assumes values up to $1 \mathrm{~mm}$ (for the L20HGSNM steel) and, given the relatively short testing time $(200 \mathrm{~h})$, it should be considered very significant. For the GS42CrMo-4 cast steel, the $\Delta \mathrm{V}$ (i) component reached high values of up to $0.8 \mathrm{~mm}$, but lower than those for the L20HGSNM cast steel. For both cast steels, it can be seen that the addition of $\mathrm{NaCl}$ to the abrasive mixture had a significant impact on the synergy of the process responsible for a destruction of surfaces of the chain wheels. As it has already been mentioned, the presence of hard products of corrosion had the highest impact on the increase in the total wear in the Variant $\mathrm{C}+\mathrm{NaCl}$. In the case of the L35GSM cast steel, the lowest values of the synergistic component, associated with the combined action of abrasive and corrosive factors (not exceeding $0.5 \mathrm{~mm}$ ) and a relatively small increase in this component in conditions of the wear intensified by the presence of $\mathrm{NaCl}$ in the abrasive mixture were observed. Figure 15 also shows how much the synergistic factor differs depending on the type of steel.

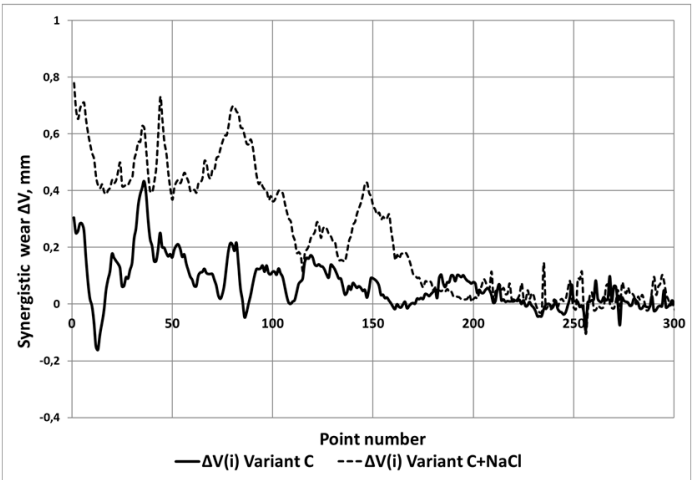

(A) GS42CrMo-4

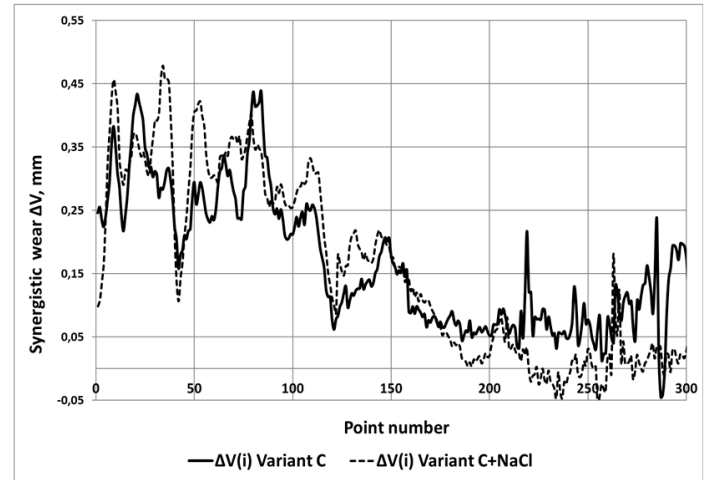

(B) L35GSM

Figure 15. Curves of synergistic component in the function of location on the $\Delta V(i)$ measurement path (A) Determined for GS42CrMo-4 steel casts, (B) Determined for L35GSM steel casts. Figure 16a presents the $\Delta V$ component in the function of the maximum strength of the analyzed steels, determined for both combinations of destructive agents: $\mathrm{SiO}_{2}+\mathrm{H}_{2} \mathrm{O}(\mathrm{Variant}$ C) and $\mathrm{SiO}_{2}+\mathrm{H}_{2} \mathrm{O}+3.5 \% \mathrm{NaCl}$ (Variant $\mathrm{C}+\mathrm{NaCl}$ ). Figure 16b, in turn, presents the proportion of the component against the abrasive wear value $\left(\Delta \mathrm{V} / \mathrm{V}_{\mathrm{M}}\right)$ of the given steel.

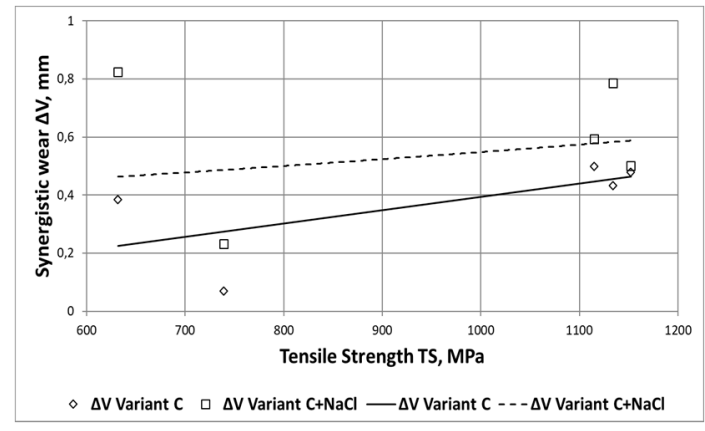

(A)

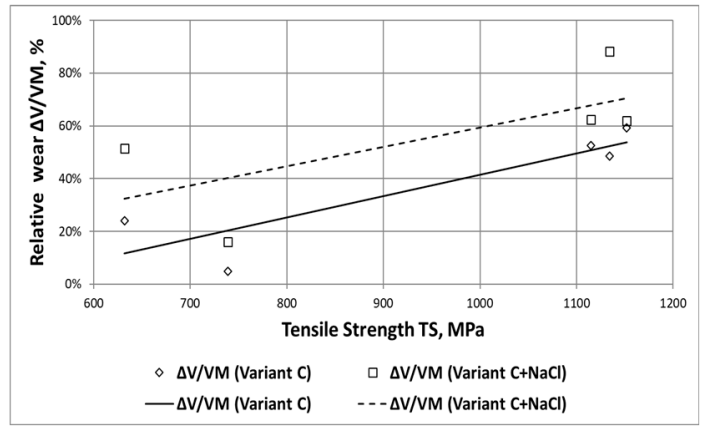

(B)

Figure 16. Synergistic components of tribocorrosion in the function of maximum strength, (A) $-\Delta \mathrm{V}$ component values, (B) -relative wear increment $\Delta \mathrm{V} / \mathrm{V}_{\mathrm{M}}$.

Based on the curves, presented in Figure 16, it is apparent that the higher the maximum strength, the greater the share of the synergistic component in the total wear. However, this observation should be taken critically because in the case of the manganese steels (L30GS, 
A6), there were unexpectedly high abrasive wear values (Variant $\mathrm{A}$ ) and the low $\Delta \mathrm{V} / \mathrm{V}_{\mathrm{M}}$ relative ratio might result from the effect of a high reference.

\section{Conclusions}

1. Based on the wear test, which simulated different abrasive and tribocorrosive wear applied on the sprockets, it can be concluded that the presence of agents intensifying the electrochemical corrosion significantly increases the total wear of the area of collaboration between the sprocket and the chain link.

2. The impact of an additional environmental factor (water), present during the exploitation in the presence of the quartz abrasive, is synergistic and affects the value of the abrasive wear in the area where the wheels interact with the chain links in all the investigated cases.

3. Adding the $3.5 \% \mathrm{NaCl}$ solution to the quartz abrasive causes a stronger synergistic effect as compared to the mixture of water and quartz abrasive (this relation was confirmed for all the analyzed materials).

4. For the analyzed materials and in tribocorrosive wear conditions, the $\Delta \mathrm{V} / \mathrm{V}_{\mathrm{M}}$ relative wear increment was $4.8 \div 59 \%$ for Variant $C$ and $15.9 \div 88.3 \%$ for Variant $\mathrm{C}+\mathrm{NaCl}$.

5 . The lowest increments of the synergistic component were recorded for the L30GS and $A 6$ steels, but this resulted from their high level of the $V_{M}$ abrasive wear reference.

Author Contributions: Conceptualization, A.N.W.; methodology, A.N.W.; formal analysis, A.N.W.; investigation, A.N.W.; data curation, A.N.W. and M.W.; writing-original draft preparation, A.N.W.; writing-review and editing, A.N.W. and M.W.; visualization, A.N.W.; supervision, A.N.W. and M.W.; project administration, A.N.W. and M.W. All authors have read and agreed to the published version of the manuscript.

Funding: The study was carried out as a part of the project "Innovative technology for production of tension members for transport systems with the use of cast materials", No. POIG.01.04.00-24-100/11.

Institutional Review Board Statement: Not applicable.

Informed Consent Statement: Not applicable.

Data Availability Statement: Not applicable.

Conflicts of Interest: The authors declare no conflict of interest.

\section{References}

1. Becker, F.; Zell, M. The state of the art in positively guided rail transport systems for underground mining. Min. Rep. 2014, 150, 34-46. [CrossRef]

2. Yaralı, O.; Yaşar, E.; Bacak, G.; Ranjith, P.G. A study of rock abrasivity and tool wear in Coal Measures Rocks. Int. J. Coal Geol. 2008, 74, 53-66. [CrossRef]

3. Wieczorek, A.N. Operation-oriented studies on wear properties of surface-hardened alloy cast steels used in mining in the conditions of the combined action of dynamic forces and an abrasive material. Arch. Metall. Mater. 2017, 62, 2381-2389. [CrossRef]

4. Wieczorek, A.N.; Stachowiak, A.; Zwierzycki, W. Experimental determination of the synergistic components of tribocorrosive wear of Ni-Cu-Mo-Ausferritic Ductile Iron. Arch. Metall. Mater. 2018, 63, 87-97.

5. Jemmely, P.; Mischler, S.; Landolt, D. Electrochemical modeling of passivation phenomena in tribocorrosion. Wear 2000, 237, 63-76. [CrossRef]

6. Celis, J.-P.; Ponthiaux, P. Testing tribocorrosion of passivating materials supporting research and industrial innovation. In European Federation of Corrosion; Maney Publishing: Leeds, UK, 2011.

7. Celis, J.-P.; Ponthiaux, P. Tribocorrosion. Wear 2006, 261, 937-938.

8. Mischler, S.; Debaud, S.; Landolt, D. Wear-accelerated corrosion of passive metals in tribocorrosion systems. J. Electrochem. Soc. 1998, 145, 750-758. [CrossRef]

9. Landolt, D. Electrochemical and materials aspect of tribocorrosion systems. J. Phys. D Appl. Phys. 2006, 39, 3121-3127. [CrossRef]

10. Watson, S.W.; Friedersdorf, F.J.; Madsen, B.W.; Cramer, S.D. Methods of measuring wear-corrosion synergism. Wear 1995, 18, 476-484. [CrossRef]

11. Landolt, D.; Mischler, S.; Stemp, M. Electrochemical methods in tribocorossion: A critical appraisal. Electrochim. Acta 2001, 46, 3913-3929. [CrossRef]

12. Stachowiak, A. Problemy Modelowania Zużywania Tribokorozyjnego w Układach Ślizgowych; Scientific Publisher of the Institute of Sustainable Technologies: Radom, Thailand, 2012. 
13. Stachowiak, A.; Zwierzycki, W. Uogólniony model zużywania tribokorozyjnego. Tribologia 2014, 2, 147-154.

14. Barril, S.; Mischler, S.; Landolt, D. Electrochemical effects on the fretting corrosion behaviour of Ti6Al4V in $0.9 \%$ sodium chloride solution. Wear 2005, 259, 282-291. [CrossRef]

15. Jiang, J.; Stack, M.M.; Neville, A. Modelling the tribo-corrosion ineraction in aqueous sliping conditions. Tribol. Int. 2002, 35, 669-679. [CrossRef]

16. Landolt, D.; Mischler, S. Tribocorrosion of Passive Metals and Coatings; Elsevier: Amsterdam, The Netherlands, 2011.

17. Fischer, A.; Mischler, S. Tribocorrosion, fundamentals, materials and application. J. Phys. D Appl. Phys. 2006, 39, 3128-3129. [CrossRef]

18. Mathew, M.T.; Srinivasa Pai, P.; Pourzal, R.; Fischer, A.; Wimmer, M.A. Significance of tribocorrosion in biomedical applications, overview and current status. Adv. Tribol. 2009, 2009, 250986. [CrossRef]

19. Tyczewski, P. Złożone warunki zużycia mechaniczno-ścierno-korozyjnego. Probl. Eksploat. 2010, 1, 63-70.

20. Tyczewski, P. Modele Interpretacyjne Mechanizmu Zużycia Ścierno-Korozyjnego. Ph.D. Thesis, Poznań University of Technology, Poznań, Poland, 2002.

21. Tyczewski, P.; Nadolny, K. Analisys of mechanical-abrasive-corrosive wear in sugar factories. Inżynieria Rol. $2007,5,409-414$.

22. Nadolny, K.; Selech, J. Ocena składowych zużycia procesów tribologicznych w środowisku ścierno-korozyjnym. J. Res. Appl. Agric. Eng. 2007, 52, 5-15.

23. Selech, J. Ocena Wpływu Stanu Warstwy Wierzchniej Materiału Na Składowe Procesu Zużycia Ścierno-Korozyjnego. Ph.D Thesis, Poznań University of Technology, Poznań, Poland, 2005.

24. Stachowiak, A.; Wieczorek, A.N. Comparative tribocorrosion tests of 30CrMo12 cast steel and ADI spheroidal cast iron. Tribol. Int. 2021, 155, 106763. [CrossRef]

25. Wieczorek, A.N.; Polis, W. Operation-oriented method for testing the abrasive wear of mining chain wheels in the conditions of the combined action of destructive factor. Manag. Syst. Prod. Eng. 2015, 5, 175-178.

26. Ibrahim, M.A.M.; Korabla, S.F.; Yoshimura, M. Corrosion of stainless steel coated with TiN, (TiAl)N and CrN in aqueous environments. Corros. Sci. 2002, 44, 815-828. [CrossRef] 